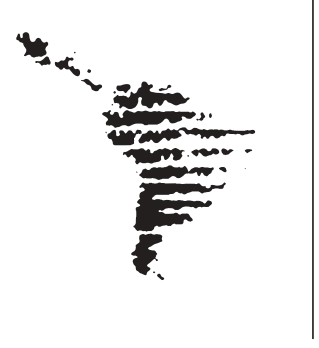

\title{
LA POLÍTICA DEL GOBIERNO MEXICANO FRENTE AL FENÓMENO MIGRATORIO
}

\author{
Alma Cossette Guadarrama Muñoz ${ }^{*}$
}

Recibido: $08 / 2009$ - A ceptado: 16/10/2009

\section{Resumen}

El objetivo de la presente ponencia es evidenciar cómo la falta de una política migratoria ha afectado las relaciones de México con otros países, principalmente los centroamericanos, por los diferentes intereses que pretende resguardar: el respeto a los derechos humanos de los extranjeros y la prohibición de transitar para las personas indocumentadas. De esta manera, se demuestra la necesidad imperante de que el gobierno mexicano cuente con una política sólida la cual incida de manera positiva en cada uno de los flujos migratorios con los que se ve afectado México al ser un país de origen, tránsito y destino.

Palabras clave: migración, México, política migratoria, migración internacional.

\section{A bstract}

This article aims to highlight that the lack of a migratory policy affects Mexican foreign affairs, especially with Central American countries, due to different interests in stake that it looks to safeguard such as foreigners human rights respect and the proscription of transit for undocumented people. It is obvious that Mexican Government needs to adopt a well grounded foreign policy with positive impact in each of the migratory flows currently affecting México, since it is a starting point, transit and destination country.

Keywords: immigration, México, immigration policy, international immigration.

\section{POSICIÓN DE MÉXICO EN EL ESCENARIO MIGRAT ORIO}

México es un estado que por su ubicación geográfica, pasado histórico y cultural li- gado a Centroamérica, y su vecindad con Estados Unidos (EU) lo colocan en una situación compleja frente al escenario de la movilidad humana debido a que en él confluyen las tres aristas de la migración, así como distintos actores que por

* Catedrática de la Facultad de Derecho, UNAM. México. 
sus características se convierten en un grupo vulnerable con la necesidad imperante de protección. De esta forma, podemos decir que México es un país de:

1. Origen. La emigración se ha utilizado como una válvula de escape para aliviar la presiones de los gobiernos, desgraciadamente, en México esta situación no es la excepción, ya que históricamente se ha mantenido una corriente de connacionales que buscan mejorar sus condiciones de vida en Estados Unidos.

2. Destino. El territorio mexicano ha sido atractivo para los extranjeros, esencialmente los inversionistas; no obstante, han existido, a lo largo de la vida nacional, diversos grupos de refugiados como los españoles en los tiempos del franquismo. Recientemente han sido los guatemaltecos, quienes, derivado de los conflictos armados en Guatemala, migraron en busca de amparo y bienestar. Este hecho obligó al gobierno a implementar diversas medidas como la instalación de campamentos en las entidades federativas del sur, el establecimiento de distintos programas de auxilio, la creación de organismos especializados en la problemática, y particularmente la reforma a la Ley General de Población (LGP) con la introducción de la figura jurídica del refugiado.

3. Tránsito. México se ve afectado con el tránsito de extranjeros quienes, por diferentes motivos, lo utilizan como puente natural con el fin de llegar a EE.UU o Canadá principalmente. Este tipo de cruce puede darse de dos for- mas: legal o ilegal; pero, es esta última corriente la que ocasiona conflictos internacionales por el choque de intereses entre las naciones involucradas. Asimismo, dentro de esta categoría, podemos incluir a los trabajadores agrícolas temporales; cada año, desde hace décadas, los guatemaltecos acuden a la zona del Soconusco para emplearse temporalmente en trabajos de pizca y limpia en distintos. El más tradicional es el del café, también el plátano, la piña, el cacao y la caña ${ }^{1}$. La presencia de este tipo de migración también asume dos modalidades, la de trabajador temporal documentado $^{2}$ e indocumentado ${ }^{3}$.

Ahora bien, sabemos que los actores principales de la migración han sido por excelencia los hombres, y, con el paso del tiempo, las mujeres. Sin embargo, cabe recordar que el estudio de este fenómeno social no es cuestión únicamente de género, porque desde esa concepción resultaría limitado; es necesario considerar como otro elemento fundamental, la edad. En otras palabras, las precarias condiciones económicas de los hogares acentuadas por la globalización y diversos factores familiares han obligado a

\footnotetext{
En años recientes se han integrado a este flujo trabajadores de otras nacionalidades como los hondureños, quienes suelen desempeñarse en la cosecha del plátano.

2 Se interna con un permiso denominado Forma Migratoria para Visitantes Agrícolas (FMVA), expedido por las autoridades migratorias.

3 Son contratados a un bajo costo por los administradores de las fincas a través de enganchadores o habilitadores. 4 Como ejemplo podemos citar a la ex Unión Soviética, que desarrolló esta política con el objetivo de expandir su territorio hacia el este, en los Urales, Siberia y la región de las estepas asiáticas.
} 
los niños y adolescentes a integrarse a estos contingentes, quienes se convirten en los protagonistas más vulnerables por sus características.

\section{TIPOS DE POLÍTICAS MIGRATORIAS}

Diversos autores se refieren a las políticas migratorias como Jordi Bonet Pérez (2003), Peter Peek y Guy Standing (1989) y Lelio Mármora (2002). Sin embargo, nos adherimos a este último, quien las clasifica en cinco tipos, cada una dirigida a una población objeto determinada:

1. Políticas de retención. Son las medidas macroeconómicas que podrían dar respuesta de fondo a los desequilibrios estructurales entre las economías de los países. Actualmente, aquellas naciones con más riquezas ofrecen remuneraciones atractivas, facilidades de trabajo, mejor nivel social y condiciones de vida; mientras que las menos favorecidas, expulsan sus recursos humanos por no contar con esas determinantes. (Mármora, 2002:180)

2. Políticas de promoción. Tienen por objetivo atraer o expulsar personas, ya sea en forma masiva o selectiva, voluntaria o forzosa, por tanto, se clasifican en:

\subsection{Programas de promoción inmigratoria. Encontramos dentro de éstos:}

\subsubsection{Los recursos humanos calificados.} Radica su importancia en las características cualitativas más que cuantitativas de los migrantes, de tal manera que todos los países de inmigración, aún los más restrictivos, están abiertos para recibir estos contingentes.

2.1.2 Los inmigrantes con inversión de capital. Se diferencian del anterior no en la calificación laboral del sujeto, sino en el capital que puede aportar.

2.1.3 La colonización. Tiene como fin el asentamiento de población en proyectos generalmente agrícolas ${ }^{4}$.

2.1.4 Las migraciones laborales. Cubren la demanda o requerimiento insatisfecho de trabajadores en el estado de destino. Se dividen en dos rubros:

2.1.4.1 Temporales. Son canalizados con fines específicos (actividades rurales, industriales, de construcción o de determinados servicios) por medio de instrumentos legales que establecen sus condiciones por un tiempo determinado.

2.1.4.2 Selectivas. Es desconocida su duración, pero no indefinida ${ }^{5}$.

Actualmente, ambos programas se encuentran vigentes en todo el mundo ${ }^{6}$, y su aplicación es considerada por muchos gobiernos como una de las alternativas de

4 Como ejemplo podemos citar a la ex Unión Soviética, que desarrolló esta política con el objetivo de expandir su territorio hacia el Este, hacia los Urales, Siberia y la región de las Estepas asiáticas. A este tipo de trabajadores se les ha denominado temporarios para diferenciarlos de los temporales.

6 Es el caso de programas temporales como el de Estados Unidos, "H2", o el que estuvo vigente en México en la década de los cuarenta, cincuenta y principio de los sesenta, llamado "Bracero". En los temporarios están el de Alemania denominado "Gastarbeuter". 
manejo adecuado de las corrientes migratorias internacionales (Mármora, 2002:244-249).

2.2 Los programas de fomento emigratorio. Estimulan la partida de individuos desde un territorio determinado. Se dividen en:

\subsubsection{Forzosos. Se han aplicado tanto a} nacionales como a extranjeros, quienes han salido bajo la figura jurídica de la deportación o exilio. 2.2.2 Voluntarios. Promueve y facilita el traslado a través de diferentes mecanismos que se ponen a disposición de los potenciales emigrantes con el objetivo básico de descomprimir los mercados de trabajo cuando la oferta supera la demanda (Mármora, 2002:249).

3. Políticas de regulación. Están dirigidas a incidir sobre los flujos migratorios establecidos, con estrategias que van desde la apertura hasta la restricción, pasando por la selectividad.

3.1 Apertura migratoria. Facilita la libre circulación de las personas a través de las fronteras. No obstante, aquellas condiciones jurídicas que permitían ejercer el ius peregrinandis pasaron de ser la norma general de movimiento por el mundo, a constituirse en la excepción para las actuales políticas (Mármora, 2002:259). En nuestros días son tres los tipos de programas que permiten seguir hablando de apertura:

\subsubsection{La reunificación familiar. A partir de} su contenido humanitario, se destaca su carácter funcional, en el que la migración familiar cumple un papel importante so- cialmente, porque se transforma en vehículo para la integración; desde el punto de vista cultural, permite amortiguar los impactos entre el individuo y el medio receptor; y, en cuanto al aspecto económico, la información y mecanismos de acceso a los mercados de trabajo que brinda la familia son cruciales para la inserción laboral del sujeto.

3.1.2 Los refugiados. Con base en un claro fundamento de protección y asistencia humanitaria, la apertura hacia los refugiados u otro tipo de migrantes forzosos ha persistido como política vigente en diferentes partes del mundo.

3.1.3 La libre circulación en los espacios de integración. Por medio de la inclusión de la variable migratoria, los países involucrados en este proceso logran la plena utilización de los recursos humanos a través de su libre movilidad entre los diferentes mercados de trabajo transnacionales. La integración territorial facilita el desplazamiento de individuos al simplificar los requisitos de entrada (Mármora, 2002:162-268).

\subsection{La restricción migratoria. Constituyen} la otra cara de las políticas de apertura en relación con sus fundamentos. Tiene como propósito impedir la entrada a un territorio a través de diferentes acciones de control que pueden derivar en otras como el castigo o la expulsión del sujeto. Giran sobre un permanente juego entre dos tipos de intereses: los del estado y los del migrante, es decir, el derecho de los gobiernos para determinar quién entra, sale o permanece en su territorio, y la prerrogativa de 
los individuos o colectividades para desplazarse y trabajar de acuerdo con su voluntad. Diferentes argumentos han sido la base para su ejecución, entre los que se pueden mencionar: la saturación de los mercados de trabajo, la presión sobre los servicios públicos a raíz de la demanda inmigratoria, la seguridad frente a problemas como el narcotráfico o el terrorismo internacional, entre otros; a partir de estos el control migratorio se orienta hacia la prevención del delito, con lo que surge inevitablemente el problema de la diferenciación entre el migrante laboral y el delincuente o terrorista. Todas estas medidas han dado lugar al fenómeno del "migrante indocumentado", por lo tanto las autoridades se han visto obligadas a ejecutar diversas acciones basadas en un estricto control de dos tipos:

\subsubsection{Fronterizo. Plantea la hipótesis de} que, con el aumento de la vigilancia en la frontera, se reduce el número de indocumentados. Al respecto, analistas del fenómeno como Wayne Cornelius, refutan esta idea argumentando que dichos mecanismos están condenados al fracaso porque no se dirigen a las causas fundamentales del fenómeno, es decir, al desequilibrio económico entre los países de acogida y los de procedencia (Mármora, 2002:290).

\subsubsection{Residencial. Se ejecuta a través de} distintos canales ya sea por medio de redadas en la vía pública, en los alojamientos frecuentemente utilizados por indocumentados, o bien, en los lugares de trabajo. En este rubro persiste una discusión sobre qué sujeto debe ser priorizado en ese control: el extranjero o quien lo aloja o lo emplea; la segunda es la más aceptada, tanto por sus posibilidades de éxito como por el tratamiento menos lesivo al migrante en función de sus derechos básicos (Mármora, 2002:290).

4. Políticas de recuperación. Su principio básico es la valorización del emigrante como recurso humano necesario para su nación. Se recupera a través del retorno físico o el posible aporte a la sociedad. Están formadas por los programas siguientes: 4.1 De retorno. Plantean algunas cuestiones como determinar el verdadero motivo del individuo para salir, prestarle ayuda para superar los problemas que le impiden repatriarse y auxiliarlo para asegurar su satisfactoria reintegración. (Mármora, 2002:297) En este sentido, las estrategias se enfocan a: _ La asistencia del repatriado voluntario. _ La identificación de los puestos de trabajo disponibles en el país de origen y la consecuente promoción del retorno de la persona adecuada. _ La inducción del regreso de emigrantes y su posterior reinserción laboral (Mármora, 2002:302).

En algunas situaciones, la repatriación es promovida por el país de origen con el objetivo de recuperar capital humano. Sin embargo, algunos autores consideran que a pesar de que los gobiernos de una u otra forma están de acuerdo con la llegada de sus emigrantes, no lo están con la idea de que sea masiva, por los problemas económico-laborales internos y el impacto de las remesas en sus economías. En otros casos, la iniciativa proviene de los estados de destino, los cuales facilitan el retorno como forma de descompresión de sus 
sociedades y mercados de trabajo, para lo cual utilizan los incentivos económicos, los cursos de capacitación laboral, o el desarrollo de proyectos en los lugares de procedencia una vez que los migrantes han regresado (Mármora, 2002:301).

\subsection{De vinculación con la población emi-} grada. Tienen como objetivo establecer y fortalecer los vínculos entre los nacionales residentes en el extranjero y la sociedad de origen. Parten del supuesto de que la emigración representa no solo pérdidas, sino también beneficios para los países, siempre y cuando sean aprovechados en sus aspectos positivos. (Mármora, 2002:316) De tal forma que estos programas están formados por dos aspectos básicos:

\subsubsection{Los motivacionales, orientados a in-} centivar las conductas de los emigrados para que adopten decisiones que beneficien al estado, a partir de cuatro diferentes acciones: _ La participación electoral a distancia, es decir que el individuo pueda elegir a los candidatos de su país al estar en el exterior, lo cual lo vincula con el quehacer nacional y le permite contribuir en la consolidación de la democracia._El otorgamiento de la doble nacionalidad propicia un vínculo psicológico más fuerte de los paisanos hacia su lugar de nacimiento, al mantenerlos involucrados con el acontecer nacional._Una política educativa bicultural válida tanto para el país de recepción como para el de origen, basada en el reconocimiento de estudios realizados en el exterior, así como en la difusión de la cultura y la realidad del lugar de procedencia entre los emigrados (Mármora, 2002:319-222).
4.2.2 Los operacionales, encargados de proveer los canales necesarios para que las decisiones de los migrantes brinden beneficios a su nación; algunos de sus programas son: la cooperación científica, técnica y tecnológica, la empresarial, la humanitaria y los flujos económicos privados. (Mármora, 2002:320) 5. Políticas de incorporación. Es en la década de los setenta, cuando las políticas de integración fueron adoptadas por gran parte de los países de destino; estas tenían como propósito principal la participación de los migrantes en las áreas social, cultural, política y económica. (Mármora, 2002:325) No obstante, determinados factores actuaron como barreras o facilitadores en el camino hacia dicha incorporación. En consecuencia, la inserción del extranjero puede ubicarse en una dicotomía participaciónmarginalidad. Entre los programas que abarcan están: 5.1 La inserción sociocultural, que puede ser:

\subsubsection{Educativa. Aparece el bilingüismo como un instrumento de integración activa?}

\subsubsection{Cultural. Parte del presupuesto de} que una recuperación y consolidación de la cultura de origen del inmigrante constituye el mejor camino para convertirlo en un elemento enriquecedor de la sociedad receptora. 5.1.3 Política. Otorga al no nacional atributos similares a las del nativo con el fin de lograr su incorporación a la vida institucional del país; con ello se fomenta su nacionalización, ya que implica

$7 \quad$ Pueden observarse programas específicos de este tipo en Australia, Suecia y Canadá. 
la posibilidad u obligación de voto. Esta idea se funda en objetivos electorales y en el principio de no marginar de la vida política y democrática a miles de personas que no cuentan con la ciudadanía (Mármora, 2002:334-335).

\subsection{Regularización de los indocumentados.} En las últimas décadas, son varios los estados que han recurrido a las regularizaciones masivas de extranjeros en situación irregular como una forma de ejercicio de sus políticas de migración internacional. Las regularizaciones se han dado como respuesta al incremento de las corrientes indocumentadas, observable en todos los países de acogida del mundo (Mármora, 2002:337).

El aumento de la brecha entre las naciones centrales y las periféricas, se traduce en diferencias abismales de empleo, salarios y condiciones de vida, que hacen que legal o ilegalmente se generen las migraciones. Para algunos analistas, este escenario provoca mayoritariamente procesos clandestinos si se dan las condiciones suficientes para que ello ocurra, es decir, la existencia dentro de las economías de los países de recepción, de sectores necesitados de mano de obra móvil y barata adaptable al contexto de trabajo normalmente rechazado por el asalariado local. Si los programas de regularización tienen como objeto principal legalizar una migración irregular, deben partir del hecho de que en ella están involucrados también los Estados de origen, por un lado, y los diferentes sectores de la sociedad de destino, por otro. Así, estos programas deben de considerar dentro de sus objetivos el con- trol y cpnocimiento de los indocumentados; su integración a la comunidad; la mejora de su condición social; la búsqueda de la transparencia en los mercados de trabajo, y la respuesta a los fines de las políticas internacionales (Mármora, 2002:339).

5.3 Inserción socioeconómica. Son acciones orientadas a incorporar adecuadamente al migrante y su familia al contexto sociolaboral del lugar de llegada a través de dos estrategias: la acción positiva ${ }^{8}$ basada en la voluntad de las empresas, las cuales se comprometen a contratar personal representativo de las minorías, especialmente afroamericanas e hispanoamericanas, $y$ publicar sus resultados; el control se ejerce con la presión del gobierno y la opinión pública; y la acción afirmativa ${ }^{9}$ destinada a restablecer la igualdad real entre los blancos y el resto de los grupos étnicos y raciales; se encuentra bajo el control de los jueces (Mármora, 2002:354-355).

\section{POLIITICA MIGRATORIA DE MÉXICO}

La posición de México, por varios años, se basó en el pensamiento de que los flujos inmigratorios eran un hecho transitorio que no llegaría a constituir un fenómeno social de alcances mayores, así que permitió que continuaran y engrosaran sin prestarles atención, al no causar conflictos internos, ni presión por parte de EU. (Bustamante, 2002:393). En consecuencia, durante los primeros años solo hubo

8 Implementada en EU.

9 Aplicada en Canadá. 
un trato individualizado a los infractores de la Ley General de Población; sin embargo, cuando el flujo aumentó, las medidas se hicieron más severas ante un suceso que para algunos se tornaba masivo, el resultado fue un reforzamiento de las prácticas de control, detención y expulsión de migrantes por parte del gobierno, acompañado de un incremento en las violaciones de derechos humanos (Castillo, 1997:208). A raíz de esta posición de contención, el Congreso mexicano aprobó en octubre de 1996, diversas modificaciones a la LGP que permitieron establecer puntos de verificación en todo el país con el fin de pedir documentos a cualquier sospechoso de ser indocumentado (Castillo, 1997:208).

Asimismo, tomando como pretexto el levantamiento guerrillero en el sur del país, ampliaron las atribuciones de los cuerpos policíacos y militares en materia de vigilancia y control migratorio, lo que les permitió entender y aplicar la ley a su libre arbitrio. De esta forma, se fue construyendo una muralla en la frontera sur como consecuencia de la militarización (Monteforte, 1996:186). Esto generó una situación de incertidumbre no solo para la comunidad migrante, sino también para la sociedad chiapaneca que se vio amenazada en su seguridad y prerrogativas. El Comité de Chihuahua Pro Defensa de Derechos Humanos afirmó que en entidades donde han intervenido elementos castrenses en labores policíacas, como Chiapas, Oaxaca y Guerrero, "se ha reportado un alto índice de violaciones a las garantías individuales como desapariciones, torturas y detenciones ilegales" (Villalpando,
2000). Esta política fue adoptada por Guatemala, desde finales de los noventa y principios del 2000, como una medida de recorrer el sellamiento de la frontera y detener de manera más efectiva las corrientes migratorias. No obstante, los atentados terroristas del 11 de septiembre de 2001 en EU, y posteriormente del 11 de marzo de 2004 en España y del 7 de julio de 2005 en Inglaterra, provocaron un repunte en las medidas de inspección, por parte de distintos países, particularmente EU, en contra de la población extranjera, a la que consideraron un peligro para la seguridad nacional y regional, ya que la identificaron como fuente de delincuencia y terrorismo potencial (IIDH, 2003:1).

Actualmente, la posición "discursiva" del gobierno mexicano acerca del fenómeno migratorio se basa en razones socioeconómicas y no en medidas de corte policíaco. Empero, en la praxis, se puede observar que sus controles hacia los transmigrantes, además de ser rigurosos, son violentos aunque permisivos con los trabajadores agrícolas. En consecuencia, esta doble moral se manifiesta por medio de su actuación en el escenario internacional, ya que por un lado protesta por las muertes de connacionales a manos de rancheros estadounidenses o grupos xenofóbicos como el Minuteman $^{10}$, al exigir respeto a sus derechos humanos; y por el otro, agentes federales, estatales y municipales mexicanos incrementan los operativos para capturar

$\overline{10}$ El movimiento Minuteman está integrado por ciudadanos voluntarios de estados fronterizos, quienes, armados con pistolas, binoculares, equipos de radiocomunicación y lámparas de alto poder, se dedican a detectar a inmigrantes que intentan alcanzar el sueño americano Véase: (s.a., 2005) . 
centroamericanos que entran por la frontera sur en condición irregular, la mayoría de las veces violando sus prerrogativas básicas.

Tal dualidad se ha mantenido y reafirmado desde que EU modificó la concepción histórica de considerar a nuestro país como parte de Centroamérica, ubicándolo estratégicamente en el norte gracias al Tratado de Libre Comercio, lo que le permitió transferir, en parte, a Centroamérica la función de México de ser su "patio trasero", al tiempo que aseguró sus fronteras mediante la firma de convenios internacionales utilizados para someter la voluntad de los estados de tránsito (Rodríguez, 2001:49). De esta manera, México quedó englobado materialmente dentro de los intereses geoestratégicos de EU dejando a nuestra soberanía nacional subordinada desde una perspectiva pragmática, a la doctrina de seguridad de Estados Unidos; con ello nuestra supuesta autonomía respecto a la política de control de las regiones fron- terizas, así como la política de relaciones exteriores con Centroamérica y el Caribe, se relativizan al estar limitadas por dicha subordinación. Desde entonces, la frontera sur, por su posición geográfica, se convirtió en un punto estratégico que orbita dentro de la seguridad nacional estadounidense (Sandoval, 1997:159-161). Por esta última razón, el gobierno mexicano está forzado a acabar con la entrada de indocumentados; para ello, ha adoptado diversos programas que hasta el momento no han logrado mantener el equilibrio entre la "facultad soberana" de decir quién entra, sale o permanece en su territorio y el respeto a los derechos humanos. A partir de lo anterior se han desarrollado diversos operativos, como el Plan Sur, cuyo objetivo es detener el tráfico de drogas, personas, contrabando de armas y vehículos robados en sentido norte-sur (BBC, 2001). Igualmente se han puesto en marcha:

\section{C uadro $\mathrm{N}^{\circ} 1$ 0 perativos realizados}

\begin{tabular}{|c|c|c|}
\hline $\begin{array}{l}\text { OPE R AT IVO } \\
\text { M ojado }\end{array}$ & $\begin{array}{c}\text { FIN } \\
\text { Deportaciones masivas }\end{array}$ & $\begin{array}{c}\text { AUTORIDAD } \\
\text { Instituto Nacional de Migración }\end{array}$ \\
\hline Río Grande & $\begin{array}{l}\text { Atajar la migración ilegal, detener a los } \\
\text { delincuentes y facilitar la entrada de ex- } \\
\text { tranjeros que cumplan con los requisitos. }\end{array}$ & $\begin{array}{l}\text { Conjuntamente con autoridades de } \\
\text { EE.UU. (s.a., 1997). }\end{array}$ \\
\hline Interferencia & $\begin{array}{l}\text { Detener a migrantes, obligándolos a de- } \\
\text { pender de los coyotes. }\end{array}$ & $\begin{array}{l}\text { Conjuntamente con autoridades de } \\
\text { EE.UU. (Campuzano, 2000:35) }\end{array}$ \\
\hline $\begin{array}{l}\text { B.O.M. (Bases } \\
\text { de Operación } \\
\text { Mixtas) }\end{array}$ & $\begin{array}{l}\text { Detener a individuos en situación } \\
\text { irregular. }\end{array}$ & $\begin{array}{l}\text { Ejército Federal, Policía Federal Preven- } \\
\text { tiva, Policía Judicial Federal y Estatal, y } \\
\text { corporaciones policíacas chiapanecas. }\end{array}$ \\
\hline Coyote & $\begin{array}{l}\text { Detectar y detener a los polleros e indi- } \\
\text { rectamente a inmigrantes. }\end{array}$ & $\begin{array}{l}\text { Conjuntamente con autoridades de } \\
\text { EE.UU. y Guatemala (IIDH, 2003:9). }\end{array}$ \\
\hline
\end{tabular}


Además, se ha incluido la creación de grupos especiales a través del Instituto $\mathrm{Na}$ cional de Migración (INM), como el denominado Grupo Especial "Cisne", establecido a finales de febrero del año 2000 , como una forma de combatir la ola de migrantes en el sur de nuestro país. Su finalidad es la captura de centroamericanos en estaciones ferroviarias, terminales de autobuses, hoteles, restaurantes, bares y centros de diversión en Talismán, Ciudad Hidalgo, Comitán, Comalapa y Tapachula. Desde entonces, la agrupación ha logrado importantes aseguramientos de indocumentados (Peters, 2000).

Con todo lo anterior, podemos afirmar que México maneja una política de regulación restrictiva tanto en el control fronterizo, demostrado con los resultados de las medidas encaminadas en ese sentido, así como en la residencia de los inmigrantes. Muestra de esto último es la modificación de las disposiciones a la Ley General de Población, que agrega el capítulo X, referente al procedimiento de verificación y vigilancia de extranjeros en el territorio naciona ${ }^{11}$, y cuya intención es facultar a la autoridad migratoria para realizar, entre otras diligencias, visitas de inspección que pueden derivar en la expulsión del sujeto en caso de irregularidad.

La contraparte a la política mencionada es la apertura, que se demostró con la introducción de la figura jurídica del refugiado en la LGP y con las facilidades otor-

11 La reforma fue aprobada el 29 de octubre de 1996 y publicada en el DOF el 8 de noviembre del mismo año. gadas por las normas para lograr la reunificación familiarr ${ }^{12}$, no así con el tema de la libre circulación en espacios de integración. Al respecto, México ha impulsado el Plan Puebla-Panamá (PPP) en el que participan ocho países centroamericanos $^{13}$. El propósito de este plan es fortalecer la integración regional e impulsar los proyectos de desarrollo social y económico a través de la construcción de carreteras y ferrocarriles, el desarrollo de las industrias de petróleo y energía eléctrica, y la creación de una gran zona de libre comercio. Sin embargo, en lo referente a la libre circulación de personas, no existe mención alguna, únicamente promueve una iniciativa denominada "Sistema de información estadístico sobre las migraciones" (Pierotti, 1998:10), que busca establecer un método de información y registro para mejorar la comprensión de este fenómeno entre los estados signatarios. Por lo anterior, se espera, como en el caso del TLC, que la "integración" sea exclusivamente comercial y permita el libre tránsito de bienes y servicios y de cierto tipo de individuos (inversionistas o empresarios), restringiendo el paso al resto de la población. Estas son dos de las razones por las

12 La LGP considera la reunificación familiar cuando el extranjero contraiga matrimonio con mexicanos o que tengan hijos nacidos en el país. De manera más específica, consagra la categoría de inmigrantes familiares para aquellos que sean cónyuges o parientes consanguíneos de algún mexicano, inmigrante o inmigrado (Artículo 39 y 48 fracción VII).

13 Belice, Costa Rica, El Salvador, Guatemala, Honduras, Nicaragua, Panamá y México. Este último incluye nueve entidades federativas del sur y sureste que son: Campeche, Chiapas, Guerrero, Oaxaca, Puebla, Quintana Roo, Tabasco, Veracruz y Yucatán. 
que existen voces en contra, además de la inconformidad por la necesidad de militarizar la región como resultado de la libre movilidad humana; la afectación a la biodiversidad a causa de la extracción indiscriminada de riqueza por parte de las corporaciones multinacionales, y la creación de maquiladoras en las zonas de libre comercio que provocarían que los campesinos se vean empujados a dejar sus tierras para convertirse en mano de obra barata de las propias industrias (CIEPAC, 2004). Dentro de las políticas de recuperación de emigrantes, concretamente en los programas de retorno, el Instituto Nacional de Migración carece actualmente de ningún tipo de programa que considere la asistencia humanitaria urgente así como la incorporación o inserción de retornados voluntarios o forzosos a las comunidades de origen.

En cuanto a los programas de vinculación con las poblaciones emigradas, estos han tenido gran auge en años recientes, como lo demuestran las reformas a la ley respecto a la no perdida de la nacionalidad, que permiten a los mexicanos por nacimiento conservarla al adquirir otra, o en el rubro de participación electoral, con la aprobación reciente del voto en el extranjero. Respecto a la comunicación con los contingentes de emigrados, se ha actuado gracias al proyecto denominado "comunidades mexicanas", cuya meta es mejorar e incrementar las relaciones con la población emigrante mediante la promoción de planes que conlleven beneficios. En política educativa también se han tenido avances con el Programa Binacional de Educación Migrante (PROBEM), que pretende asegurar la continuidad y la equidad de la educación básica para niños y jóvenes que cursan una parte del año escolar en México y otra en EE.UU. Asimismo, se cuenta con el programa denominado "Paisano"14, cuyo fin es facilitar y dar seguridad a la entrada de mexicanos y extranjeros a través de la coordinación de acciones entre diversas dependencias. El propósito es brindar información precisa y atención eficiente en trámites y recepción de quejas.

No podemos decir que el gobierno mexicano haya tenido una política de promoción emigratoria forzosa ni de nacionales ni de extranjeros, aun cuando a lo largo de nuestra historia se han presentado exilios y expulsiones ${ }^{15}$; inclusive, estas últimas se hallan consagradas en el artículo 33 de la Constitución. En contrario sensu, la emigración voluntaria, ha estado presente con mayor fuerza a partir del gobierno del presidente Miguel Alemán Valdés (1946-1952), y se considera desde entonces como "algo que había que alentar o preservar porque aliviaba las presiones sobre el gobierno y la sociedad que producían la pobreza, el desempleo y la injusta distribución de la riqueza, sobre los sectores de la población y sobre las regiones del

14 En este programa, considerado como de retorno, es necesario tomar en cuenta que no toda la población a la que va dirigida tiene como propósito la repatriación voluntaria; la gran mayoría son solo visitantes temporales.

15 Entre 1910 y 1920 se produjo el mayor número de exiliados mexicanos pertenecientes a diferentes facciones como zapatistas, villistas, científicos, porfiristas, entre otros. Véase: (Lerner, 2004). En el rubro de expulsiones, el caso más reciente es el de dos jóvenes españoles deportados de México por haber participado en una manifestación de exbraceros. Véase: (s.a., 2004). 
país de donde provenían los migrantes que se iban a buscar trabajo a Estados Unidos" (Bustamante, 2002). Nos referimos a los Convenios de Braceros ${ }^{16}$, cuyo objetivo fue el reclutamiento y empleo de ciudadanos mexicanos para cubrir las necesidades de mano de obra en los campos agrícolas y en los ferrocarriles estadounidenses. Empero, estos convenios fracasaron porque las autoridades tanto mexicanas como norteamericanas encargadas de vigilar que se cumplieran las condiciones bajo las cuales se habían pactado, no lo hicieron, al grado de que la situación de trabajo de los braceros no logró distinguirse de la de los indocumentados quienes se empleaban en las mismas fincas (García y Griego y Vere Campos, 1988:72). Una vez concluido el acuerdo, el descuento del 10\% hecho por patrones al salario del migrante en bancos designados por el gobierno mexicano, no les fue regresado (por ignorancia o porque no lo reclamaron en su momento). Actualmente, estos adeudos han adquirido el rango de deuda pública porque fueron firmados con base en el artículo 133 constitucional por el poder ejecutivo y ratificados por el Senado de la República (Bustamante, 2003:3).

Frente a esta situación, existen opiniones a favor y en contra sobre la viabilidad real de este tipo de convenios. Un ejemplo de las voces que se alzan en contra es la del expresidente López Portillo, quien manifestaba que "los convenios de braceros lo único que hacen es aislar el problema sin resolverlo en cuanto al fondo" (SPyP,

16 Vigentes desde 1942 hasta que EU los concluyó el 30 de mayo de 1963.
1980:12). Otra postura, en este sentido, es la del exdirector de El Colegio de la Frontera Norte, Jorge Bustamante (2002), quien se opone porque:

1. El gobierno los usó como una válvula de escape para aliviar las presiones provenientes del desempleo en el campo y las condiciones de extrema pobreza.

2. La responsabilidad de cumplir con la protección de los mexicanos en el extranjero fue evadida ante la sociedad civil, que se mostró indiferente por las condiciones de abuso y discriminación sufridas por los connacionales.

3. El trabajo de los braceros fue sacrifica$\mathrm{do}^{17}$. Entre las posturas a favor podemos mencionar la del Doctor José Juan De Olloqui y Labastida, para quien el convenio es una fórmula compartida de solucionar y controlar la emigración de nacionales a EE.UU., como se menciona en la siguiente cita: "Desde hace treinta años, vengo insistiendo en que la única solución a corto plazo es un acuerdo o convenio de braceros, $(\ldots)$ en los Estados Unidos lo que ha limitado en parte el crecimiento de su economía y competitividad con algunos países, no ha sido la falta de capital, de tecnología o de capacidad gerencial, sino que el cuello de botella,... han sido los problemas relativos a mano de obra" (De Olloqui, 2001:11).

$\overline{17}$ Jorge Bustamante basa su opinión estrictamente en la experiencia de los convenios firmados entre México y EE.UU. por ello, agrega a los elementos mencionados la posición de los trabajadores agrícolas en el ámbito jurídico, es decir, el problema en la aplicación de acuerdos bilaterales de este tipo, que son de competencia federal y la ley laboral que es de ámbito local. 
Particularmente, compartimos la visión de Bustamante, en el sentido de que los convenios de braceros fueron utilizados como una salida falsa, a través de la cual el gobierno estadounidense ganó en mano de obra barata. El mexicano alivió sus presiones sociales, pero los braceros perdieron al trabajar en condiciones precarias y al descontarles el 10\% aplicado a sus salarios para asegurar su regreso, sin poder, hasta la fecha, recuperarlo ${ }^{18}$. No obstante, no concordamos con quienes dicen que este tipo de programas son inconvenientes porque aíslan el problema. Aquí nos adherimos a la posición del doctor De Olloqui; si tales proyectos son encuadrados dentro del marco de una clara política migratoria podrían tener resultados satisfactorios. El fracaso por la mala administración y control de los convenios firmados con el gobierno estadounidense no implica que no funcionen; hay que distinguir entre la corrupción que originó ese desenlace específico y la factibilidad de éxito de programas similares como una forma de dirigir las corrientes migratorias al satisfacer tanto los intereses de los países involucrados como los de los migrantes. Por ello, pensamos que la idea sigue siendo atractiva, siempre y cuando en su diseño y aplicación se tomen en cuenta aspectos como: -La corrección de los errores cometidos en el pasado. -El ejercicio de un verdadero control sobre la emigración. -El planteamiento de los convenios como una línea de acción y no como eje dentro de las políticas migratorias.

18 Actualmente, el gobierno mexicano, para solucionar la deuda con los exbraceros, ha formando un fideicomiso para cubrir , a mediano plazo, el adeudo.
Dentro de los programas de promoción inmigratoria, México ha tenido especial interés en aquellos dirigidos a la inversión de capital y a la selección de recursos humanos calificados; empero, ha puesto poca atención en las migraciones temporales, especialmente de guatemaltecos en la región sur; por consiguiente, el gobierno de Guatemala ha formulado varios reclamos ante las violaciones a los derechos humanos de sus nacionales. A raíz de esto, nuestro gobierno emprendió diversas acciones como la credencialización de visitantes agrícolas (FMVA) ${ }^{19}$, lo cual agilizó el control de los ingresos y salidas a través de un código de barras. Asimismo, permitió realizar entradas múltiples con libre tránsito en Chiapas y les brindó seguridad jurídica a los portadores frente a cualquier autoridad. A estas acciones, se une la creación de un grupo ad-hoc sobre trabajadores temporales guatemaltecos, en el marco de las reuniones bilaterales (Vid infra, 16), que quedó oficialmente instalado el 12 de febrero de 2002, y entre cuyos objetivos está la elaboración de un diagnóstico en la materia.

México no cuenta con una política de incorporación de extranjeros a la sociedad. Esto se puede apreciar en los ámbitos educativo, cultural y político, en los que no hay estrategias específicas que estimen su inserción en estos campos. En el primero, hay programas de educación bilingüe, pero en un número reducido por parte de la iniciativa privada; por parte del gobierno, únicamente están enfocados a los grupos indígenas; en cuanto al tema cultural, se

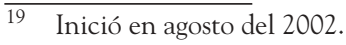


desconoce la aplicación de algún plan, y finalmente, en el plano político, si bien es cierto que los extranjeros gozan de las mismas prerrogativas que la Constitución otorga a los mexicanos, también es que estas garantías están limitadas en diferentes áreas, como la posibilidad de votar o ser votados. En programas de regularización para migrantes, México ha puesto en operación varios de manera intermitente, como el que estuvo vigente de enero a diciembre de 2004, para los no inmigrantes que por distintos motivos no tenían la documentación vigente y en regla ${ }^{20}$. Respecto a la inclusión socioeconómica, nuestro país, a diferencia de otras naciones, no cuenta con medidas como la acción afirmativa o positiva; luego entonces, no hay estrategias claras que consideren la inserción de los extranjeros en la vida económica del país.

En las políticas de retención, el éxito en la aplicación unilateral de los programas para detener los recursos humanos orientando sus capacidades y habilidades no basta; es necesario destruir la barrera generada por el desequilibrio entre las economías débiles y fuertes. En este sentido, la política migratoria de México, dada su ubicación geográfica, debe estar orientada no solo a contener a la población susceptible de emigrar, sino también a la de aquellos países expulsores. Frente a esta dicotomía, se han firmado 11 tratados $^{21}$

20 Durante este período se regularizaron 4356 extranjeros, de los cuales el 49, 5\% fueron hombres y el $50,5 \%$ mujeres.

21 En América los tratados son: el Acuerdo de Complementación Económica México-Uruguay, firmado el 29 de diciembre de 1999 en Montevideo; el Tratado de Libre Comercio de América del Norte comerciales con naciones de diferentes continentes, de los cuales 8 son naciones de América, sin incluir el Acuerdo de Libre Comercio de las Américas (ALCA) que impulsa el gobierno de EU con el fin de crear una zona de libre comercio en el Norte, Centro y Sur del Continente Americano. El ALCA operará de manera similar al TLC, y por supuesto, estará restringida la libertad de movimiento para las personas (CRM, 2001:10).

No obstante, el gobierno mexicano, junto con los demás países de origen de emigrantes, debe tomar en cuenta que las políticas

(EU-Canadá-México), firmado el 17 de diciembre de 1992 en México, Ottawa y Washington, vigente desde el $1^{\circ}$ de enero de 1994; el Tratado de Libre Comercio de México-Bolivia, firmado el 10 de septiembre de 1994 en Río de Janeiro y en vigor desde el 1 de enero de 1995; el Tratado de Libre Comercio México-Chile, firmado el 17 de abril de 1998 en Santiago de Chile y vigente desde agosto de 1999; el Tratado de Libre Comercio México-Costa Rica, firmado el 5 de abril de 1994 en la ciudad de México y en vigor desde el 1 de enero de 1995; el Tratado de Libre Comercio de Grupo de los Tres (México-Colombia-Venezuela), firmado el 13 de junio de 1994 en Cartagena de Indias y que entró en vigor el $1^{\circ}$ de enero de 1995 el Tratado de Libre Comercio México-Nicaragua firmado el 18 de diciembre de 1997 en Managua y vigente desde el 1 de junio de 1998; el Tratado de Libre Comercio México-Triángulo del Norte (Guatemala, Honduras y El Salvador), que se firmó ad referéndum el 29 de junio de 2000 en la Ciudad de México y vigente desde enero de 2001 (no tiene referencia al fenómeno migratorio). Con países del continente europeo son sólo dos: el Tratado de Libre Comercio México-Unión Europea, que entró en vigor el $1^{\circ}$ de julio de 2000 y el Tratado de Libre Comercio México-Asociación Europea. Finalmente con Asia y Medio Oriente únicamente es uno, el Tratado de Libre Comercio México-Israel firmado el 10 de abril del 2000 en la ciudad de México y vigente desde el $1^{\circ}$ de julio de 2000. 22 Como ejemplo mencionamos el Programa Nacional de Fondos Comunitarios implementado en Guatemala. Su objetivo es convertir a sus migrantes y ciudadanos residentes en socios del fondo y posteriormente en agentes financieros. 
para retener a su población no pueden ser unilaterales sino multilaterales. Por tanto, la unión de esfuerzos la cooperación económica mediante la inversión externa y el impulso de mecanismos de desarrollo, que coadyuven a crear las condiciones que mejoren la competitividad y abran oportunidades de inversión, al tiempo que permitan habilitar el capital local al incentivar las exportaciones. Aquí, la utilización de las remesas surge como una posible herramienta para encauzar los objetivos de estas políticas con planes orientados a sacar el mayor provecho a este tipo de recursos para las familias de los emigrantes.

Asimismo, como una forma de combatir el fenómeno de la inmigración, se ha implementado el Programa de Desarrollo Fronterizo (PRODESFRO), vigente desde 1995, cuya intención es alcanzar un desarrollo sostenible para la región sur, basado en cuatro ejes principales: mejora e impulso de la infraestructura; ejecución de proyectos que involucran el crecimiento económico productivo; impulso a las comunidades, y conservación del ambiente y sitios arqueológicos (Dardon, 2002:329). No obstante, desde su creación y hasta la fecha no se han tenido grandes avances en el cumplimiento de sus propósitos, de hecho se desconocen sus logros. Nuestro país ha formado parte de diversos organismos con miras a controlar la migración como 1. Proceso Puebla. Producto de la Cumbre de Presidentes denominada Tuxtla II, efectuada en Puebla en febrero de 1996, de la cual nace la primera Conferencia Regional sobre Migraciones (CRM) conocida también como Foro Puebla, el cual representa un mecanismo de diálogo multicultural, que permite la reflexión y la coordinación política entre las naciones miembro que comparten desde distintas perspectivas el fenómeno de la migración forzada por razones económicas (OIM, 2001:63).

\section{Grupo Binacional México-Guatemala} sobre asuntos migratorios. La relación entre México y Guatemala es de tensión fluctuante y se halla entre la proximidad y la distancia, como lo señala Castillo. (2000:193-218) De esta forma, cuando Guatemala ha tenido regímenes democráticos (1944-1954), el trato ha sido de cooperación, comprensión, y amistad; por el contrario, cuando ha caído en manos de dictaduras militares, se ha tornado tensa y hostil. A últimas fechas, con el gobierno de Vinicio Cerezo Arévalo (1985), las relaciones se modificaron y se reestablecieron (Arriola, 1995:109). Esto se reflejó en el Grupo de Trabajo Binacional MéxicoGuatemala creado en 1986 bajo la tutela de los cancilleres respectivos; en su segunda reunión, el 18 de agosto de 1989, se estableció un grupo de trabajo sobre asuntos migratorios ratificado el 20 de abril de 1990. Su fin fue abocarse a estudiar las medidas para la integración de la cooperación binacional en materia migratoria en torno a tres temas fundamentales: flujos documentados, indocumentados y corrientes de indocumentados de terceros países. Asimismo, ha buscado intercambiar información; coordinar esfuerzos para el combate de figuras delictivas que graviten sobre los migrantes; propiciar medidas que prevengan su explotación por grupos delictivos organizados; difundir normas y controles migratorios y asegurar 
el respeto a los derechos humanos de inmigrantes (OIM, 2002:3).

\section{El Grupo Binacional México-Belice. Es} el mecanismo más importante de diálogo y cooperación bilateral entre México y Belice. Desde su creación en abril de 1990 ha llevado a cabo 5 reuniones ${ }^{22}$, la última en Ciudad de Belice, encabezada por los Cancilleres Luis Ernesto Derbez y Godfrey Smith, respectivamente. Entre los aciertos de este grupo podemos mencionar el proyecto de construcción del nuevo puente internacional que unirá a las dos naciones; la revisión de los temas correspondientes a las áreas de seguridad fronteriza, migración y consular; el acuerdo para supresión de visas en pasaportes diplomáticos, y la creación del Grupo de Alto Nivel de Seguridad Fronteriza (GANSEF). (SRE, 2005) Con todo lo expuesto, podemos afirmar que, si bien México ha implementado políticas de incorporación, recuperación, promoción y retención, es en las de regulación, y particularmente restrictiva, donde ha puesto mayor énfasis, por lo que los migrantes hablan de una nueva frontera, antes invisible, la que divide México de Guatemala, y que para los centroamericanos se ha convertido en lo que para los mexicanos es la de Estados Unidos: una barrera casi infranqueable. De esta forma, al imaginariamente recorrerse el "muro" de la frontera de Estados Unidos al sur de México, Guatemala se convierte no solo en receptor, sino en el destino final de los indocumentados.

22 En abril de 1990, noviembre de 1993 y 1995, y en enero de 1998 y 2005. Véase: (Embajada de México en Belice, 2005).

\section{CON CLUSIONES}

La posición geográfica de México ha hecho que su política migratoria esté fundamentada en una regulación represiva, la cual ha producido que el efecto deseado resulte a la inversa, es decir, en lugar de que el flujo migratorio disminuya, ha aumentado. En la actualidad, el país se halla en una situación irrisoria al demandar respeto por los derechos humanos de los mexicanos al tiempo de violar los de los centroamericanos con la militarización de su frontera. No obstante, el gobierno mexicano tiene el derecho de establecer las providencias que juzgue convenientes para permitir el paso de un extranjero a su territorio, así como establecer un control al momento de entrar, salir o durante su estancia; empero, dichas medidas deben ser mesuradas tomando en cuenta que no son resolutorias. En otras palabras, las restricciones serían como una piedra que intenta frenar el caudal de un río, el resultado, termina siendo absorbida o en el mejor de los casos logra desviar el cauce, pero no impide que siga fluyendo ${ }^{23}$.

Si el citado cauce es orientado hacia las regiones que lo requieren, dejaría de ser de un problema para convertirse en una solución. Por ello, en tanto México no tenga una política migratoria bien definida y equilibrada, basada en programas y estrategias, que consideren una reforma

23 Es el caso de Estados Unidos, que al construir el muro fronterizo con el fin de frenar el paso de migrantes a su territorio, lo único que logró fue trasladar la ruta migratoria al estado de Arizona, en donde, a pesar del desierto y los peligros que este representa, los indocumentados siguen arriesgando sus vidas. 
integral a la Ley General de Población, la pretendida gobernabilidad sobre la movilidad humana seguirá siendo un sueño inalcanzable, que en realidad es condicionada y dirigida por EU.

La migración es un fenómeno social, que involucra invariablemente a varios países, por lo que su solución no puede ser pensada desde un punto de vista unilateral, sino multilateral en el cual también estén presentes el resto de los países de Centroamérica, que irrumpen en el escenario internacional con sus contingentes. Empero, la posición de estas naciones ha sido, por un lado de un carácter defensivo ante las violaciones de que son víctimas sus ciudadanos sin ofrecerles estrategias eficaces de protección; y por otro, de cierta dosis de oportunismo, ya que la emigración de sus poblaciones constituye una válvula de escape para aliviar las presiones generadas por las frecuentes crisis y la entrada de una buena cantidad de divisas producto de las remesas. En este sentido, cada país busca resolver los problemas creados por la migración de acuerdo con sus intereses; las naciones de origen están preocupadas por el impacto de las remesas y el bienestar de sus compatriotas; mientras que las de recepción lo están por el impacto en los mercados laborales, el control de las fronteras y los procedimientos de admisión y expulsión. La forma en que han sido abordadas estas preocupaciones son aceptables en tanto que inciden de los modos ya explicados en sus sociedades, sin embargo, no le dan una solución definitiva, porque son apreciadas desde la óptica individualista fundamentada en el beneficio personal y el legítimo interés de defensa, cuan- do lo que se necesita son mecanismos eficaces y expeditos, que incidan en las causas de la migración, así como una sincera colaboración multilateral a partir de la aceptación de una corresponsabilidad en el fenómeno migratorio por parte de los estados de expulsión, tránsito y destino.

No debemos olvidar que la tendencia mundial está encaminada hacia una integración territorial condicionada por la globalización, lo cual exige la libertad de movimiento de capitales, bienes y personas (incluidos los trabajadores temporales); por consiguiente, los gobiernos están obligados a contribuir en la toma de decisiones y acciones inmediatas con el fin de controlar y dirigir adecuadamente los flujos migratorios.

\section{PROPUESTAS}

La magnitud del fenómeno migratorio con el que se ve afectado México imposibilita pensar en una solución mágica e inmediata, pero sí en una serie de medidas urgentes y eficaces encaminadas a la protección de los derechos fundamentales y la integridad física de la personas, independientemente del estatus migratorio, a través de:

1. La estructuración de una política migratoria sólida, que perdure por varios sexenios, basada en cuatro aspectos fundamentales que tendrían que ser las líneas de acción de las cuales deriven los programas pertinentes dirigidos a cada población en concreto. Hablamos de retención y recuperación de emigrantes cuyas, remesas se constituyan como vehículo de inserción en la

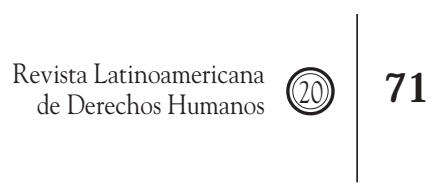


sociedad; promoción emigratoria e inmigratoria a través de convenios temporales que comprometan a los estados involucrados; incorporación permanente de inmigrantes y valoración de la apertura en espacios de integración por encima de la restricción.

2. La reforma a la Ley General de Población y su Reglamento con una visión humanista, integral y completa, acorde con la realidad que vive el México del siglo XXI como país de origen, tránsito y destino, al privilegiar la condición de ser humano sobre la nacionalidad.

3. Incorporación a la legislación interna de los tratados internacionales en la materia.

4. La cooperación con las naciones de origen y destino con el fin de lograr la gobernabilidad sobre la migración a través del consenso, tolerancia, solidaridad y crecimiento económico para lograr un efectivo control y dirección dentro de un marco de respeto a los derechos fundamentales de los migrantes independientemente de su situación jurídica.

\section{Bibliografía}

Dogmática, A.M. (1995): Tapachula "La perla del Soconusco". Guatemala: FLACSO.

Bonet, J. (2003): Las políticas migratorias y la protección internacional de los Derechos y Libertades de los Inmigrantes. Bilbao: Universidad de Deusto.

Bustamante, J. (2002): Migración internacional y derechos humanos. México: UNAM.

(2003). El marco jurídico de la migración y de los derechos humanos de los migrantes. México: Instituto de Investigaciones Jurídicas (IIJ).

Castillo, M.A. (1997). "Las políticas migratorias de México y Guatemala en el contexto de la integración". En P. Bovin (coord): Las fronteras del istmo. Fronteras y sociedades entre el sur de México y América Central. México: CIESAS y Centro Francés de Estudios Mexicanos y Centroamericanos. Castillo, M.Á. (2000). "La vecindad MéxicoGuatemala: una tensión entre proximidad y distancia”. En: Estudios Demográficos y Urbanos, México, volumen 14, núm. 1.

Campuzano, M. (2000). "La migración a Estados Unidos”. Letras Libres. México, núm. 17.

Centro de Investigaciones Económicas y Políticas de Acción Comunitaria (CIEPAC). (2004). El Plan Puebla Panamá (PPP). México. Consultado en http:// www.ciepac.org/archivo/ppp.htm.

Conferencia Regional sobre Migraciones (CRM) (2001). Incertidumbre, azar e inequidad. Informe sobre los derechos humanos de los migrantes en situaciones de intercepción, detención, deportación y recepción en los países miembros de la Conferencia Regional sobre Migración. México.

Dardon, J. (2002). Caracterización de la fronterade Guatemala/México. Guatemala: FLACSO.

De Olloqui, J.J. (Comp.) (2001). Estudios en torno a la Migración. México: UNAM. 
Embajada de México en Belice. (2005). Grupo Binaciona". México. Consultado en: http://www.sre.gob.mx/belice/politicaexterior/mexybel.htm\#D.

García y Griego, M. y Vere C. M. (1998). México y Estados Unidos frente a la migración de los indocumentados. México: Porrúa.

Instituto Interamericano de Derechos Humanos (IIDH) (2003). Seminario taller: Hacia una estrategia regional de protección de los derechos de las poblaciones migrantes. Costa Rica.

Internet British Broadcasting Corporation (BBC). (2001). El desafío en la frontera sur, México. Consultado en: http:// news.bbc.co.uk/hi/spanish/specials/newsid_1426000/1426334.stm

Mármora, L. (2002). Las Políticas de migraciones internacionales. Buenos Aires: OIMPaidós.

Monteforte, M. (1996). La frontera móvil. México: UNAM.

Pierotti, I. (Coord.) (1998): Contribución a la reflexión sobre el fenómeno de la migración femenina en Guatemala. Guatemala: Movimondo.

Peek, P. y Standing, G. (1989). Políticas de Estado y Migración. México: El Colegio de México.

Sandoval, J.M. (1997). "La región fronteriza sur de México en la perspectiva de la seguridad nacional estadounidense". En: Philippe Bovin (coord). Las Fronteras del Istmo. Fronteras y Sociedades entre el sur de México y América Central. Centro de Investigaciones y Estudios Superiores en Antropología Social y Centro Francés de Estudios Mexicanos y Centroamericanos. México, D.F. Pp. 155-162.

Periódicos [s.a.] (2005): "Amenazan Minuteman a Inmigrantes”, Puntual, México. [s.a.] (1997): "EE.UU. aumenta acciones contra inmigrantes ilegales", Prensa Libre, Guatemala.

Peters, M. de J. (2000). "Cacería de ilegales", Prensa Libre, Guatemala.
Rodríguez, H. (2001): "No todos los coyotes son de la misma loma", Voces del tiempo. Guatemala, num. 37. Documentos.

Secretaría de Programación y Presupuesto (SPyP) (1980). Indocumentados. México, num. 44.

Secretaría de Relaciones Exteriores (SRE) (2005). V reunión binacional. México. Consultado en: http://www.sre.gob.mx/comunicados/comunicados/2005/enero/ b_014.htm.

Organización Internacional para las Migraciones (OIM) (2002). Cuaderno de trabajo sobre migración: Acuerdos del Grupo Binacional Guatemala-México sobre asuntos migratorios. Guatemala, núm. 10.

Organización Internacional para las Migraciones (OIM). (2001). "El proceso Puebla: Principales logros y desafíos". Costa Rica. Consultado en: http://www.iom.int/CostaRica/webdocs/Puebla.PDF.

Lerner, V. (2004). Estados Unidos frente a las conspiraciones fraguadas en su territorio por exiliados de la época de la revolución, México. UNAM. Consultado en: http://www. ejournal.unam.mx/historia_moderna/ ehm19/EHM01904.pdf.

[s.a.] 2004. México: Dos españoles expulsados por manifestarse. México. Consultado en: http://acp.sindominio.net/article. pl?sid=04/08/27/0015242.

Villalpando, R. (2000). Se suman a las BOM miembros del Ejército. México, La jornada. Consultado en: http://www.jornada.unam. mx/2000/sep00/000910/020n3gen.html. 
